\title{
Fertility Status of Soil in the Tea Garden Belts of Golaghat District, Assam, India
}

\author{
Bhupen K. Baruah, ${ }^{1}$ Bhanita Das, ${ }^{2}$ Chitrani Medhi, ${ }^{1}$ and Abani K. Misra ${ }^{1}$ \\ ${ }^{1}$ Department of Chemistry, Gauhati University, Guwahati 781014, India \\ ${ }^{2}$ Department of Statistics, Gauhati University, Guwahati 781014, India
}

Correspondence should be addressed to Bhupen K. Baruah; bhupen_baruah2009@rediffmail.com

Received 14 December 2011; Accepted 4 June 2012

Academic Editor: Ludo Diels

Copyright ( 2013 Bhupen K. Baruah et al. This is an open access article distributed under the Creative Commons Attribution License, which permits unrestricted use, distribution, and reproduction in any medium, provided the original work is properly cited.

\begin{abstract}
The increasing land use intensity without adequate and balanced use of chemical fertilizers and with little or no use of organic manure have caused severe fertility deterioration of our soils resulting in stagnating or even declining of crop productivity in Assam. The need of the hour is to achieve substantially higher crop yield than the present yield levels from our limited land resources on a sustainable basis. A study was carried out in the paddy fields of tea garden belts namely, Rungagora, Balijan, Banwaripur, Khomtai, Rungajaun, Lattakoojan, Borjan, Behora, Negheriting, and Borsapori of Golaghat district of Assam to investigate the fertility status of soil during 2008-2010. Results of the present study showed that soil solutions were acidic in nature in all seasons. Medium-tohigh $\mathrm{BD}$, medium SOM, medium-to-high available $\mathrm{N}$ and available phosphorous, and low availability of potash showed that soils were not sufficiently fertile for crop production. Depending on the SOM, available N, available P, and exchangeable K in soil, the study areas were grouped in to six fertility classes as MMML, MMHL, MMMM, MHHL, MHHM, and MMHM. Student $t$-test values of all the parameters with control sample showed statistically significant results for SOM, available $\mathrm{N}$, and available $\mathrm{P}$ in both seasons (dry and wet) and EC in wet seasons and bulk density in dry season only.
\end{abstract}

\section{Introduction}

Soil quality is the capacity to function effectively at present and in the future [1]. According to Karlen et al., soil quality is the capacity of soil to function within natural or managed ecosystem boundaries, to sustain plant and animal productivity, maintain or enhance water and air quality, and support human health and habitation [2]. Soil quality cannot be measured directly; it must be inferred from a wide range of soil quality properties (physical, chemical, and biological) that influence the capacity of soil to perform effectively. Hence, identification of soil quality indicators and assessment approaches is further complicated by the multiplicity of physical, chemical, and biological factors that interact and control soil functions [3]. It also varies with time, climate, rainfall, and plants and human factors $[4,5]$.

With the advancement of science and technology and the increase in population, urbanization, and industrialization, the demand of soil for diverse purposes such as construction, industrial, and agricultural is increasing continuously, thereby decreasing soil quality drastically. According to Lal and Singh, soil quality degradation process with reference to productivity or fertility encompasses physical, chemical, and biological degradation processes [6]. The main reasons of soil quality degradation in irrigated areas are the inadequate and unbalanced application agrochemicals (fertilizers, pesticides, herbicides, and insecticides) to soil $[7,8]$. In cropping systems, intensive soil tillage practices especially in the tropical and subtropical climate accelerate soil erosion and loss of organic matter as well as considerable amount of nutrients resulting in soil quality degradation [9]. Besides, frequently occurred dry spells during rainy season and short winters due to rise in temperature have also enhanced soil fertility deterioration in agricultural areas [10].

The improvement of soil quality is critical to sustaining agricultural productivity and has recently received much 
attention [11]. Soil fertility deterioration is a major constraint for higher crop production in Assam. Intensive agriculture without adequate and balanced use of chemical fertilizers, non-ecofriendly tillage practices, and with little or no use of organic manure caused severe fertility deterioration of our agricultural soils resulting in stagnating or even declining of crop productivity [12]. In the present study area of Golaghat district, rice (Oryza sativa) and tea (Camellia sinensis var. assamica) are the predominant crops. The farmers of this area used on average $182 \mathrm{~kg}$ nutrients/ha annually $(132 \mathrm{~kg} \mathrm{~N}$ $+27 \mathrm{~kg} \mathrm{P}+17 \mathrm{~kg} \mathrm{~K}+4 \mathrm{~kg} \mathrm{~S}$, and $2 \mathrm{~kg} \mathrm{Zn)} \mathrm{[13].} \mathrm{Fertilizer}$ sources were urea for $\mathrm{N}$, SSP for P, and muriate of potassium for K. Frequent use of chemical fertilizers to soil results in steady decline in fertility and loss of productivity. The same is true in Assam, where the main attention has been focused on maximizing yield using nitrogenous chemical fertilizers. The over use of NPK fertilizers not only affects on the soil quality, also affects on carbohydrate and protein content of wheat, maize, grams, and so forth grown on overfertilized soil $[8,14]$. The vegetables and fruits grown on overfertilized soil are more prone to attacks by insects and diseases $[15,16]$. The demand for increasing rice production is mounting up to feed the ever-increasing population in Assam. To meet the food requirement of ever-increasing human population, there is important need of high crop productivity rate, which is only possible when soil is fertile. The knowledge of the fertility status of soil is very much essential for judicious application of fertilizers and its amendments for higher crop production [17].

Soil testing plays an important role in the use of fertilizers and other agricultural inputs. Soil test summaries and soil fertility maps are of vital necessity as reference materials for scientific management of soil. Different indicators and parameters such as soil texture, bulk density (BD), water holding capacity (WHC), $\mathrm{pH}$, electrical conductance (EC), soil organic matter (SOM), available nitrogen (AN), available phosphorous (AP), exchangeable potash (AK), and concentrations of macro/micronutrients are appropriate for describing soil quality and agricultural productivity [18-20] The need of the hour is to achieve substantially higher crop yield than the present yield levels from our limited land resources. Thus the present study was undertaken to draw a general picture of fertility level of soils in and around tea garden belts of Golaghat district of Assam in order to strengthen the national and local soil quality database so that purpose-oriented soil assessments and predictions can be made in the area. This information will also help to adopt effective strategy on fertilizer use and cropping pattern.

\section{Experimental}

2.1. Soil Sampling. Twenty representative sites from the paddy fields in and around ten tea garden belts were selected for the characterization of the soil samples. The paddy fields were characterized by traditional rice cropping system with low-medium productivity, poor irrigation, and unbalanced fertilizers use. Moreover, the paddy fields of the sampling sites were subjected to irrigation waste disposal from tea gardens as well as domestic wastes and rice-straw residues. Soil samples from the surface soil to a depth of $0-15 \mathrm{~cm}$ were collected from the paddy fields of 10 tea garden areas, namely, Rungagura, Borjan, Balijan, Lattakoojan, Banwaripur, Borsapori, Negheriting, Koomtai, and Behora TE. Two composite samples (5/6 samples per sites) from each tea garden belts were collected randomly in polythene bags, as per the standard procedures recommended by [2123]. Representative soil sample from paddy fields that was free from waste water and irrigational waste disposal was also collected as control sample. Soil sampling was done seasonally for two wet seasons (April-October) and two dry seasons (November-March) between 2008 and 2010. Soil samples were air dried and crushed and homogenized and passed through a $2 \mathrm{~mm}$ sieve and stored in polythene bags for physical and chemical analysis.

2.2. Soil Analysis. Physico-chemical properties of soil samples were measured following the laboratory procedures described by [21-24]. Soil pH and EC were determined using a digital $\mathrm{pH}$-meter (Eutech-356C, India), digital conductivity meter (ATC-975-C, India) and respectively. The SOM content was determined by Walkley Black dichromate method [25]. Available P was determined following the standard procedure described in [23]. Available $\mathrm{N}$ in soil was estimated by alkaline permanganate method [26]. Bulk density of the soil was determined by cylindrical tube core method [27].

\section{Results}

The estimated values of most sensitive soil quality indicators, namely, pH, EC, BD, SOM, available $\mathrm{N}$, available P, exchangeable $\mathrm{K}$, and soil texture after triplicate measurements in each case are presented in Tables 1 and 2 .

$\mathrm{pH}$ of soil samples were found acidic in reaction in both the seasons. The range of $\mathrm{pH}$ in dry season and wet season was 4.78-6.03 and 4.71-6.01, respectively. $\mathrm{pH}$ value in the dry season was found to be slight higher than the wet season. Lowest $\mathrm{pH}$ was recorded at Rungajaun TE belt (4.78 and 4.71), and the highest was recorded at Behora TE belt (6.03 and 6.01) in both the seasons. $\mathrm{pH}$ of controlled sample during dry and wet season was found to be 6.10 and 5.63, respectively. The study revealed that $\mathrm{pH}$ of majority of soil samples was below the acceptable range of irrigation water (6.0-8.5). Comparison of the mean values of soil $\mathrm{pH}$ in both the seasons with the mean $\mathrm{pH}$ of control samples was found insignificant.

Season-wise estimated EC values indicated that larger amount of ionic matter was present in soil samples during dry seasons than the wet seasons (Table 1). During wet seasons, maximum EC was recorded at Khomtai TE belt $(231.27 \mu \mathrm{S} / \mathrm{cm})$ and the minimum was recorded at Banwaripur TE belt $(131.84 \mu \mathrm{S} / \mathrm{cm})$, whereas the maximum and the minimum during dry season were recorded at Rungajaun TE belt $(238.50 \mu \mathrm{S} / \mathrm{cm})$ and Rungagora TE $(137.19 \mu \mathrm{S} / \mathrm{cm})$, respectively. The EC of soil samples were found decreasing during wet seasons than the dry seasons in all TE belts 
TABLE 1: Season-wise estimated values of soil pH, electrical conductance (EC), bulk density (BD), and soil organic matter (SOM).

\begin{tabular}{|c|c|c|c|c|c|c|c|c|}
\hline \multirow{2}{*}{ Name of TE } & \multicolumn{4}{|c|}{ Dry season } & \multicolumn{4}{|c|}{ Wet season } \\
\hline & $\mathrm{pH}$ & $\mathrm{EC}(\mu \mathrm{S} / \mathrm{cm})$ & $\mathrm{BD}(\mathrm{gm} / \mathrm{cc})$ & SOM (\%) & $\mathrm{pH}$ & $\mathrm{EC}(\mu \mathrm{S} / \mathrm{cm})$ & $\mathrm{BD}(\mathrm{gm} / \mathrm{cc})$ & SOM (\%) \\
\hline Rungagora & 5.24 & 137.19 & 1.34 & 2.47 & 5.21 & 160.23 & 1.03 & 2.56 \\
\hline Borjan & 5.17 & 159.87 & 1.07 & 4.99 & 5.13 & 155.43 & 0.92 & 5.71 \\
\hline Negheriting & 5.42 & 155.12 & 1.35 & 5.02 & 5.35 & 153.49 & 0.77 & 5.45 \\
\hline Balijan & 4.98 & 179.29 & 1.42 & 2.78 & 4.78 & 174.23 & 1.23 & 2.92 \\
\hline Banwaripur & 5.08 & 138.94 & 1.21 & 6.23 & 5.01 & 131.84 & 0.98 & 6.45 \\
\hline Khomtai & 5.37 & 232.55 & 0.97 & 2.87 & 5.35 & 231.27 & 0.91 & 3.04 \\
\hline Rungajaun & 4.78 & 238.50 & 1.08 & 4.35 & 4.71 & 201.49 & 1.02 & 5.03 \\
\hline Borsapori & 4.83 & 189.25 & 1.28 & 2.24 & 4.82 & 187.93 & 1.25 & 2.67 \\
\hline Lattakoojan & 5.37 & 171.10 & 1.09 & 2.93 & 5.31 & 167.83 & 0.98 & 3.12 \\
\hline Behora & 6.03 & 191.83 & 1.24 & 5.56 & 6.01 & 187.58 & 1.19 & 5.22 \\
\hline Control & 6.10 & 176.67 & 0.97 & 5.52 & 5.63 & 178.35 & 0.91 & 5.67 \\
\hline$t$-value & $0.87^{*}$ & $2.69^{*}$ & $0.23^{* *}$ & $0.78^{* *}$ & $0.46^{*}$ & $3.22^{* *}$ & $0.11^{*}$ & $0.69^{* *}$ \\
\hline
\end{tabular}

Significant at $5 \%$ probability level, ${ }^{*}$ not significant.

TABLE 2: Season-wise estimated values of soil available nitrogen, exchangeable potash $\left(\mathrm{K}_{2} \mathrm{O}\right)$, and available phosphorouss $\left(\mathrm{P}_{2} \mathrm{O}_{5}\right)($ in $\mathrm{Kg} / \mathrm{ha})$.

\begin{tabular}{|c|c|c|c|c|c|c|}
\hline \multirow{2}{*}{ Name of TE } & \multicolumn{3}{|c|}{ Dry season } & \multicolumn{3}{|c|}{ Wet season } \\
\hline & Available N & Available P & Exchangeable K & Available N & Available P & Exchangeable K \\
\hline Rungagora & 350.41 & 36.78 & 90.23 & 342.73 & 35.43 & 87.01 \\
\hline Borjan & 465.52 & 58.12 & 97.56 & 469.64 & 57.30 & 92.88 \\
\hline Negheriting & 480.11 & 35.87 & 78.61 & 484.82 & 35.09 & 67.69 \\
\hline Balijan & 435.20 & 79.02 & 97.99 & 561.31 & 80.56 & 39.71 \\
\hline Banwaripur & 398.74 & 37.15 & 89.29 & 274.10 & 38.29 & 80.93 \\
\hline Khomtai & 467.27 & 37.34 & 101.10 & 460.38 & 36.22 & 105.23 \\
\hline Rungajaun & 502.35 & 48.29 & 109.78 & 488.15 & 57.46 & 101.04 \\
\hline Borsapori & 354.62 & 49.38 & 107.39 & 367.23 & 48.67 & 102.11 \\
\hline Lattakoojan & 402.60 & 26.50 & 104.32 & 436.50 & 25.39 & 98.19 \\
\hline Behora & 455.48 & 38.41 & 88.27 & 432.30 & 39.64 & 80.25 \\
\hline Control & 433.29 & 38.29 & 105.08 & 430.71 & 36.88 & 104.61 \\
\hline$t$-value & $2.06^{* *}$ & $6.39^{* *}$ & $0.67^{*}$ & $1.01^{* *}$ & $1.10^{* *}$ & $3.01^{*}$ \\
\hline
\end{tabular}

Significant at $5 \%$ probability level, ${ }^{*}$ not significant.

TABLE 3: Classification of soil samples on the basis of soil organic matter (SOM), available nitrogen (AN), potash as $\mathrm{K}_{2} \mathrm{O}$ (EK), and phosphorous as $\mathrm{P}_{2} \mathrm{O}_{5}$ (AP).

\begin{tabular}{|c|c|c|c|c|c|c|c|c|}
\hline \multirow{2}{*}{ Name of TE } & \multicolumn{4}{|c|}{ Dry season } & \multicolumn{4}{|c|}{ Wet season } \\
\hline & SOM & $\mathrm{AN}$ & $\mathrm{AP}$ & EK & SOM & AN & AP & EK \\
\hline Rungagora & $\mathrm{M}$ & $\mathrm{M}$ & $\mathrm{M}$ & $\mathrm{L}$ & $\mathrm{M}$ & $\mathrm{M}$ & $\mathrm{M}$ & $\mathrm{L}$ \\
\hline Borjan & M & $\mathrm{M}$ & $\mathrm{H}$ & $\mathrm{L}$ & M & $\mathrm{M}$ & $\mathrm{M}$ & $\mathrm{L}$ \\
\hline Negheriting & M & $\mathrm{M}$ & $\mathrm{M}$ & $\mathrm{L}$ & M & $\mathrm{M}$ & $\mathrm{M}$ & $\mathrm{L}$ \\
\hline Balijan & M & $\mathrm{M}$ & $\mathrm{H}$ & $\mathrm{L}$ & M & $\mathrm{H}$ & $\mathrm{H}$ & $\mathrm{L}$ \\
\hline Negheriting & M & $\mathrm{M}$ & M & $\mathrm{L}$ & M & $\mathrm{M}$ & $\mathrm{M}$ & $\mathrm{L}$ \\
\hline Khomtai & M & $\mathrm{M}$ & $\mathrm{M}$ & $\mathrm{M}$ & M & $\mathrm{M}$ & $\mathrm{M}$ & M \\
\hline Rungajaun & M & $\mathrm{H}$ & $\mathrm{H}$ & M & M & M & $\mathrm{H}$ & M \\
\hline Borsapori & M & $\mathrm{M}$ & $\mathrm{H}$ & $\mathrm{M}$ & M & $\mathrm{M}$ & $\mathrm{H}$ & M \\
\hline Lattakoojan & M & $\mathrm{M}$ & M & M & M & $\mathrm{M}$ & $\mathrm{M}$ & $\mathrm{L}$ \\
\hline Behora & M & $\mathrm{M}$ & $\mathrm{M}$ & $\mathrm{L}$ & M & $\mathrm{M}$ & $\mathrm{M}$ & $\mathrm{L}$ \\
\hline Control & M & M & M & M & M & $\mathrm{M}$ & M & M \\
\hline
\end{tabular}

L: Low, M: Medium, H: High [12]. 
except Rungagora TE where EC was found to be increased from 137.19 to $160.23 \mu \mathrm{S} / \mathrm{cm}$. Study also revealed that the difference between the mean EC of soil samples in dry season was found to be insignificant but significant during wet season compared with the control sample.

The bulk density of soil is inversely related to the porosity of the same soil. High bulk density is an indicator of low soil porosity and soil compaction. The maximum and minimum $\mathrm{BD}$ of soil in dry season in the tea gardens belts of the study area was found $1.42 \mathrm{gm} / \mathrm{cc}$ and $0.97 \mathrm{gm} / \mathrm{cc}$ at Balijan TE belt and Khomtai TE belt, respectively. The mean value of soil $\mathrm{BD}$ during dry season was also found $0.97 \mathrm{gm} / \mathrm{cc}$. Whereas in wet season it was found $1.25 \mathrm{gm} / \mathrm{cc}$ and $0.77 \mathrm{gm} / \mathrm{cc}$ at Borsapori TE belt and Negheriting TE belt, respectively. Comparison of mean values with the mean value of controlled samples was found statistically significant in dry seasons but insignificant during wet seasons.

Classification of soil samples on the basis of SOM showed that soil samples collected from Borjan, Negheriting, Rungajaun, Banwaripur, and Behora TE belts were within safe limit $(>4 \%)$, and the others were found in between $2-4 \%$ in both the seasons. SOM of all the samples was found to be higher in wet season compared with the dry season except Behora TE belt (5.56-5.22\%). Comparison of mean values with the mean value of control samples was found statistically significant in both the seasons. Soil available $\mathrm{N}$ was found within the medium range $(250-500 \mathrm{Kg} / \mathrm{ha})$ in majority of the soil samples except samples from Rungajaun TE belt in dry season and Balijan TE tea belts in wet season. The range was $350.41-502.35 \mathrm{Kg} / \mathrm{ha}$ and $274.10-561.31 \mathrm{Kg} / \mathrm{ha}$ during dry and wet season, respectively. Comparison of mean values from both the seasons with control samples found to be statistically insignificant. Samples of Balijan TE were found changing medium category $(250-500 \mathrm{~kg} / \mathrm{ha}$ ) to high category $(>500 \mathrm{Kg} / \mathrm{ha})$ in available $\mathrm{N}$ from dry season to wet season. Other samples were found within the medium category in both seasons. Available phosphorous as $\mathrm{P}_{2} \mathrm{O}_{5}$ in all samples in both the seasons, found to be in the medium-to-high category. The range of available $\mathrm{P}$ was $(26.50-79.02 \mathrm{Kg} / \mathrm{ha})$ and $(25.39-80.56 \mathrm{Kg} / \mathrm{ha})$ in dry and wet season, respectively. Minimum was recorded at Lattakoojan TE belts, and the maximum was found at Balijan TE in both the seasons. Comparison of mean values from both the seasons with control samples was found to be statistically insignificant. Soil exchangeable potassium as $\mathrm{K}_{2} \mathrm{O}$ in both the seasons was found within low category $(<100 \mathrm{Kg} / \mathrm{ha})$ in majority of the samples (Table 2). The maximum and minimum values during dry season were recorded at Negheriting $\mathrm{Te}$ belt $(78.61 \mathrm{Kg} / \mathrm{ha})$ and Rungajaun TE belt $(109.78 \mathrm{Kg} / \mathrm{ha})$, whereas during wet season it was recorded at Khomtai TE belt $(105.23 \mathrm{Kg} / \mathrm{ha})$ and Balijan TE belt $(39.71 \mathrm{Kg} / \mathrm{ha})$, respectively. Comparison of mean values of exchangeable $\mathrm{K}$ in both the seasons with the mean values of the control samples showed a statistically insignificant result. Depending on the SOM, available N, available P, and exchangeable $\mathrm{K}$ in soil, the soils of the tea garden belts of Golaghat district were grouped into six fertility classes as MMML, MMHL, MMMM, MHHL, MHHM, and MMHM. Soil fertility group along with the sampling stations are presented in Table 3.

\section{Discussions and Conclusion}

The results of soil $\mathrm{pH}$ data showed that it was slightly declined in the wet season in all the locations due to runoff of nutrients in the rainy seasons. It has been well established that continuous exposure of soil to highly alkaline irrigation effluents leads to salinity in soils making it unsuitable for irrigation purposes $[17,28]$. Soil samples were found more acidic in wet seasons than the dry seasons by the leaching effect of rain water during summer, which replaces basic cations $\left(\mathrm{Ca}^{2+}, \mathrm{Mg}^{2+}, \mathrm{Na}^{+}\right.$and $\left.\mathrm{K}^{+}\right)$with $\mathrm{H}^{+}$ions. Use of long-term inorganic fertilizers instead of green manure, farmyard manure, and rice-straw residues had also enhanced in decreasing soil $\mathrm{pH}[29]$.

Estimated values of soil $\mathrm{pH}$ indicated that micronutrients $\mathrm{Fe}, \mathrm{Cu}, \mathrm{Zn}$, and $\mathrm{Mn}$ in soil were more available to plant $[9,30]$. Due to low $\mathrm{pH}$ of soil, $\mathrm{NO}_{3}^{-}-\mathrm{N}$ and $\mathrm{NH}_{4}^{+}-\mathrm{N}$ were less available to plants in the study area as soil $\mathrm{pH}$ range 6.0 to 8.5 makes them more available to plants [31]. The availability of N, P, $\mathrm{K}, \mathrm{Ca}, \mathrm{Mg}$ decreases with the decrease in $\mathrm{pH}$ below 5.5-6.6 [23]. Soil $\mathrm{B}$ and $\mathrm{Ca}$ content and microbial populations in the study area might not be deficient as soil $\mathrm{pH}$ below 5.0; $\mathrm{B}$ and $\mathrm{Ca}$ become less available and microbial populations decrease considerably [9]. The acidic nature of soil and availability of micronutrients to plants in the present study showed a considerable variation with the rainfall distribution, relative humidity, and temperature variation [30]. Due to high rainfall and higher temperature in wet seasons, paddy fields were found to be slightly nutrient-deficient compared with the dry seasons.

The EC results suggested that soils were moderate to high in electrolyte concentration in both the seasons. The increase in EC value may be due to agricultural run off from the tea gardens and domestic waste water disposal. Low soil EC in wet season is due to higher leaching induced by heavy rainfall in the absence of adequate amount of soil organic matter or may be due to decomposition of organic matter at high temperature [10].

The mean bulk density of soil samples of the study area showed low permeability due to medium-to-high bulk density and thereby decreasing soil porosity. It means that plant roots were often physically impeded by compact subsoil layers [32]. This soil BD result of the present study implied that the subsoil of the area cannot hold sufficient amount of available nutrients and water. Soils in the area were often too sticky when wet and too hard when dry to cultivate. There were increases in bulk density in dry season than wet season, and this possibly was as a result of the confounding effects of natural- and tillage-induced compaction during paddy seasons. Due to low-medium range of soil BD and porosity the rate of leaching of major cations in wet season was higher than dry seasons and hence, low soil $\mathrm{pH}$. The bulk density of soil also varies with tillage methods, ploughing depths, and manure application [20].

SOM results suggested that agricultural soils of the study area promote soil aggregation, prevent losses of nutrient, and enhance the mineralization of organic $\mathrm{N}, \mathrm{P}$, and $\mathrm{S}$ making a suitable environment for plant growth [20] Organic matter content thus may serve as a reservoir of plant nutrients 
promoting water storage as well as microbial activity. Organic carbon content of surface soil increased significantly in wet seasons in all sampling sites with incorporation of waste organic substances present in paddy fields. Application of domestic waste products, green manure, farmyard manure, and rice-straw residue in conjunction with fertilizer in paddy fields by the rural people of the study area might also increased SOM in wet seasons.

The study showed a significant difference in an available $\mathrm{N}$ content of surface soil in wet season to dry seasons. Available $\mathrm{N}$ content in wet season was found to be higher in majority of the soil samples, which might be due to the extensive application nitrogenous fertilizers and also the decomposition of domestic waste product in aqueous environment. Increase in available $\mathrm{N}$ in surface soil might be attributed to the direct addition of nitrogen through farmyard manure and green manure to the available pool of the soil. The favorable soil conditions under inorganic fertilizers and green manure addition might have helped in the mineralization of soil $\mathrm{N}$ leading to buildup of higher available $\mathrm{N}[10,33]$. Classification of available $\mathrm{P}$ in soil samples showed medium to-high-category, and it was found to be decreased from dry season to wet season during the study. Higher amount of SOM in wet seasons enhances the mineralization of organic $\mathrm{P}$ to available $\mathrm{P}$ but due to higher rainfall and higher rate of decomposition of SOM may increase the leaching of available P from surface soils [10].

The exchangeable K content of surface soil in crop fields was found in low to medium category in both the seasons during the study. Due to smaller size of $\mathrm{K}^{+}$ion, it can be easily leached from the surface soil during the rainy seasons resulting in significant difference in soil available $\mathrm{K}$ from dry season to wet seasons [34, 35]. Continuous use of fertilizers and intensive cropping had resulted in lowering the potassium status of soil indicating the need to apply the potassium to meet the crop requirement [16]. Moreover, farmers of the study area applied higher amount of nitrogenous fertilizers than P-type and K-type fertilizers resulting in decrease in soil available $\mathrm{P}$ and exchangeable $\mathrm{K}$.

The study was the understanding of the complex nature of soil using an integrated approach. It shows a way towards identifying the procedures to arrive at soil quality indicators, which can be applied to monitor soil quality of rice fields and support management decisions. Socioeconomic issues also have a strong effect on soil quality. Hence, the soil quality assessments were successful in reconciling farmers' and scientific knowledge. The results indicate that without both local and scientific knowledge, a satisfactory level of crop production and the maintenance of soil quality cannot be achieved at the same time. Therefore, researchers must continue to face the challenge to provide a base for bridge building between farmers' and scientists' knowledge. Reconciling local and scientific knowledge is one of the most important steps towards evaluating the feasibility of alternative production systems and the sustainability of land use in terms of long-term soil quality.

The study disapproved the apprehension that the use of chemical fertilizers over the years may impair the soil fertility on long-term basis. Even application of nutrient
(NPK), if applied in recommended dose, could sustain the productivity and soil fertility of the system. Now, it is the demand of the time to develop an integrated inorganicorganic soil fertilization programme for higher crop yield and for improved soil health. We may not achieve the goal of increased and sustained soil productivity without inclusion of integrated inorganic-organic soil fertilization programme with special attention.

\section{References}

[1] J. W. Doran and T. B. Parkin, "Defining and assessing soil quality," in Defining Soil Quality for Sustainable Environment, J. W. Doran et al., Ed., pp. 3-21, American Society of Agronomy, Madison, Wis, USA, 1994.

[2] D. L. Karlen, M. J. Mausbach, J. W. Doran, R. G. Cline, R. F. Harris, and G. E. Schuman, "Soil quality: a concept, definition, and framework for evaluation: (a guest editorial)," Soil Science Society of America Journal, vol. 61, no. 1, pp. 4-10, 1997.

[3] J. W. Doran and T. B. Parkin, "Quantitative indicators of soil quality: a minimum data set," in Methods for Assessing Soil Qualit, J. W. Doran et al., Ed., pp. 25-37, Soil Science Society of America, Madison, Wis, USA, 1996.

[4] M. A. Arshad and S. Martin, "Identifying critical limits for soil quality indicators in agro-ecosystems," Agriculture, Ecosystems and Environment, vol. 88, no. 2, pp. 153-160, 2002.

[5] J. W. Doran, "Soil health and global sustainability: translating science into practice," Agriculture Ecosystem \& Environment, vol. 88, pp. 119-127, 2002.

[6] R. Lal and B. R. Singh, "Effects of soil degradation on crop productivity in East Africa," Journal of Sustainable Agriculture, vol. 13, no. 1, pp. 15-36, 1998.

[7] B. Majumdar, M. S. Venkatesh, K. K. Satapathy, K. Kumar, and Patiram, "Effect of alternative farming systems to shifting cultivation on soil fertility," Indian Journal of Agricultural Sciences, vol. 72, no. 2, pp. 122-124, 2002.

[8] M. P. Sharma, P. Bali, and J. P. Gupta, Annals of Agricultural Research, vol. 24, no. 1, pp. 91-94, 2003.

[9] D. L. Sparks, Environmental Soil Chemistry, Academic Press, San Diego, Calif, USA, 2nd edition, 2003.

[10] J. S. Urkurkar, A. Tiwari, S. Chitale, and R. K. Bajpai, "Influence of long-term use of inorganic and organic manures on soil fertility and sustainable productivity of rice (Oryza sativa) and wheat (Triticum aestivum) in Inceptisols," Indian Journal of Agricultural Sciences, vol. 80, no. 3, pp. 208-212, 2010.

[11] M. M. Pulleman, J. Bouma, E. A. van Essen, and E. W. Meijles, "Soil organic matter content as a function of different land use history," Soil Science Society of America Journal, vol. 64, no. 2, pp. 689-693, 2000.

[12] P. K. Barua and P. K. Bora, "Fertility status of the soils of North Eastern region," Journal of the North Eastern Council, vol. 1, no. 2, pp. 21-26, 1975.

[13] Statistical Hand Book of Assam, Directorate of Economics and Statistics, Government of Assam, Guwahati, India, 2009.

[14] M. P. Yadav, A. Mohd, and S. P. Kushwaha, "Effect of integrated nutrient management on rice (Oryza sativa)-wheat (Triticum aestivum) cropping system in central plains zone of Uttar Pradesh," Indian Journal of Agronomy, vol. 50, no. 2, pp. 89-93, 2005.

[15] M. I. Sultani, M. A. Gill, M. M. Anwar, and M. Athar, "Evaluation of soil physical properties as influenced by various 
green manuring legumes and phosphorus fertilization under rain fed conditions," International Journal of Environmental Science and Technology, vol. 4, no. 1, pp. 109-118, 2007.

[16] S. R. Singh, M. Y. Zargar, U. Singh, and M. Ishaq, "Influence of bio-inoculants and inorganic fertilizers on yield, nutrient balance, microbial dynamics and quality of strawberry (Fragariax ananassa) under rainfed conditions of Kashmir valley," Indian Journal of Agricultural Sciences, vol. 80, no. 4, pp. 275-281, 2010.

[17] P. K. Barua and P. K. Bora, Progress of Soil Testing Works in Assam, Summary Report of the Soil Testing Laboratory (from Inception to 1969), Soil Fertility Series No.1, Department of Agriculture, Assam, India, 1969.

[18] R. A. Bowman, M. F. Vigil, D. C. Nielsen, and R. L. Anderson, "Soil organic matter changes in intensively cropped dryland systems," Soil Science Society of America Journal, vol. 63, no. 1, pp. 186-191, 1999.

[19] J. Lampurlanés and C. Cantero-Martínez, "Soil bulk density and penetration resistance under different tillage and crop management systems and their relationship with barley root growth," Agronomy Journal, vol. 95, no. 3, pp. 526-536, 2003.

[20] C. Palm, P. Sanchez, S. Ahamed, and A. Awiti, "Soils: a contemporary perspective," Annual Review of Environment and Resources, vol. 32, pp. 99-129, 2007.

[21] L. A. Richards, Diagnosis and Improvement of Saline and Alkaline Soil, vol. 60 of US Department of Agriculture Hand Book, United States Salinity Laboratory Staff, 1986.

[22] M. L. Jackson, Soil Chemical Analysis, Prentice Hall, New Delhi, India, 1973.

[23] P. C. Jaiswal, Soil, Plant and Water Analysis, Kalyani, Assam, India, 2nd edition, 2006.

[24] R. K. Trivedi and P. K. Geol, Chemical and Biological Methods for Water Pollution Studies, Environmental Publications, Maharashtra, India, 1986.

[25] A. Walkely and I. A. Black, "An examination of the degtjareff method for determining soil organic matter, and a proposed modification of the chromic acid titration method," Soil Science, vol. 37, pp. 29-38, 1934.

[26] C. A. Black, Methods of Soil Analysis, Part II, American Society of Agronomy, Madison, Wis, USA, 1965.

[27] S. L. Chopra and J. S. Kanwar, Analytical Agricultural Chemistry, Kalyani, New Delhi, India, 1986.

[28] R. N. Prasad and Patiram, Annual Report ICAR Research Complex for North Eastern Hill Region, Meghalaya, India, 1981.

[29] K. N. Tiwari, Fundamental of Soil Science, Indian Society of Soil Science, New Delhi, India, 2003.

[30] R. A. Khattak and Z. Hussain, "Evaluation of soil fertility status and nutrition of orchards," Soil \& Environment, vol. 26, no. 1, pp. 22-32, 2007.

[31] S. Rao, "Analysis of soil for available major nutrients," in Methods of Analysis of Soils, Plants, Water and Fertilizers, H. L. S. Tandon, Ed., pp. 13-35, Fertilizer Association and Consultation Organization, New Delhi, India, 2001.

[32] K. K. Borah, B. Bhuyan, and H. P. Sarma, "Variation of bulk density and organic matter in soils of tea garden belt of undivided Darrang district, Assam," Archives of Applied Science Research, vol. 1, no. 2, pp. 159-164, 2009.

[33] M. Sharma, B. Mishra, and R. Singh, "Long-term effects of fertilizers and manure on physical and chemical properties of a mollisol," Journal of the Indian Society of Soil Science, vol. 55, no. 4, pp. 523-524, 2007.
[34] M. Albaji, A. Landi, B. S. Nasab, and K. Moravej, "Land suitability evaluation for surface and drip irrigation in shavoor plain iran," Journal of Applied Sciences, vol. 8, no. 4, pp. 654-659, 2008.

[35] B. Behera, S. G. R. Maruthi, S. K. Mohanty et al., "Sustainable fertilizer practices for upland rice (Oryza sativa) from permanent manurial trials under subhumid alfisols," Indian Journal of Agronomy, vol. 52, no. 2, pp. 96-101, 2007. 

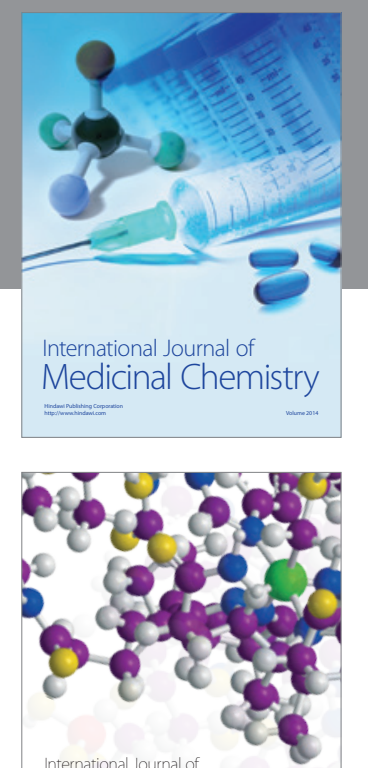

\section{Carbohydrate} Chemistry

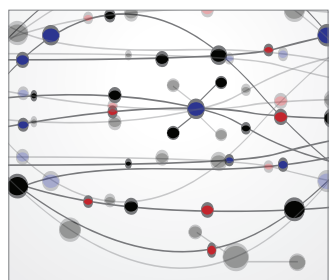

The Scientific World Journal
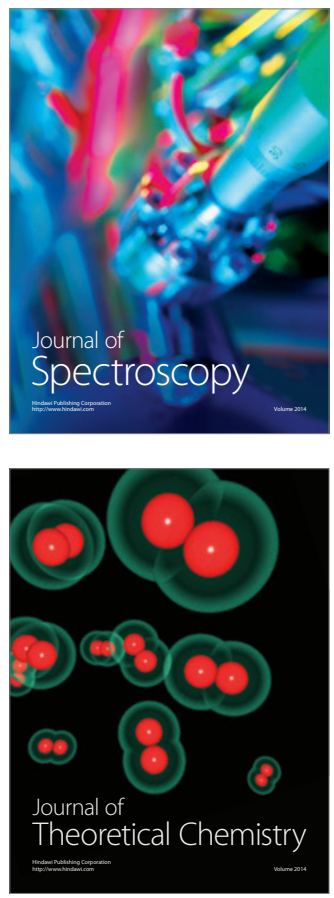
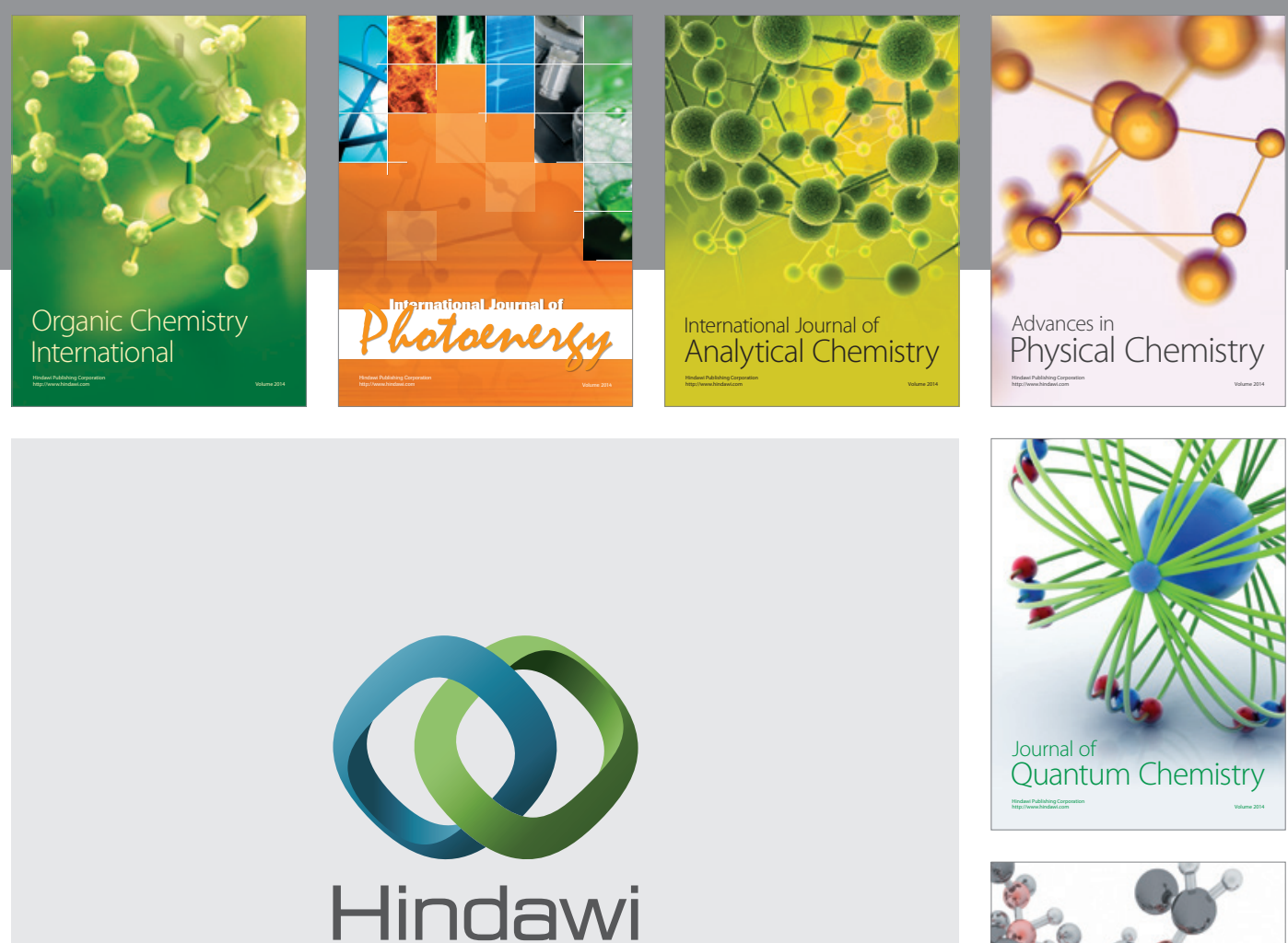

Submit your manuscripts at

http://www.hindawi.com

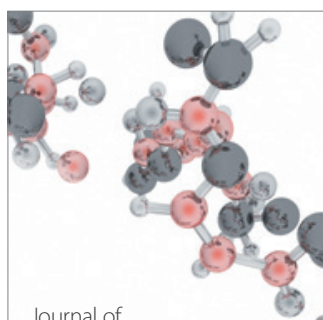

Analytical Methods

in Chemistry

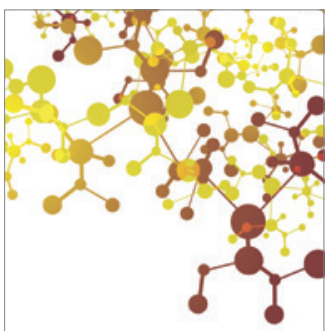

Journal of

Applied Chemistry

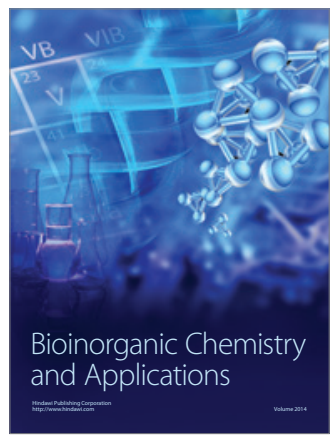

Inorganic Chemistry
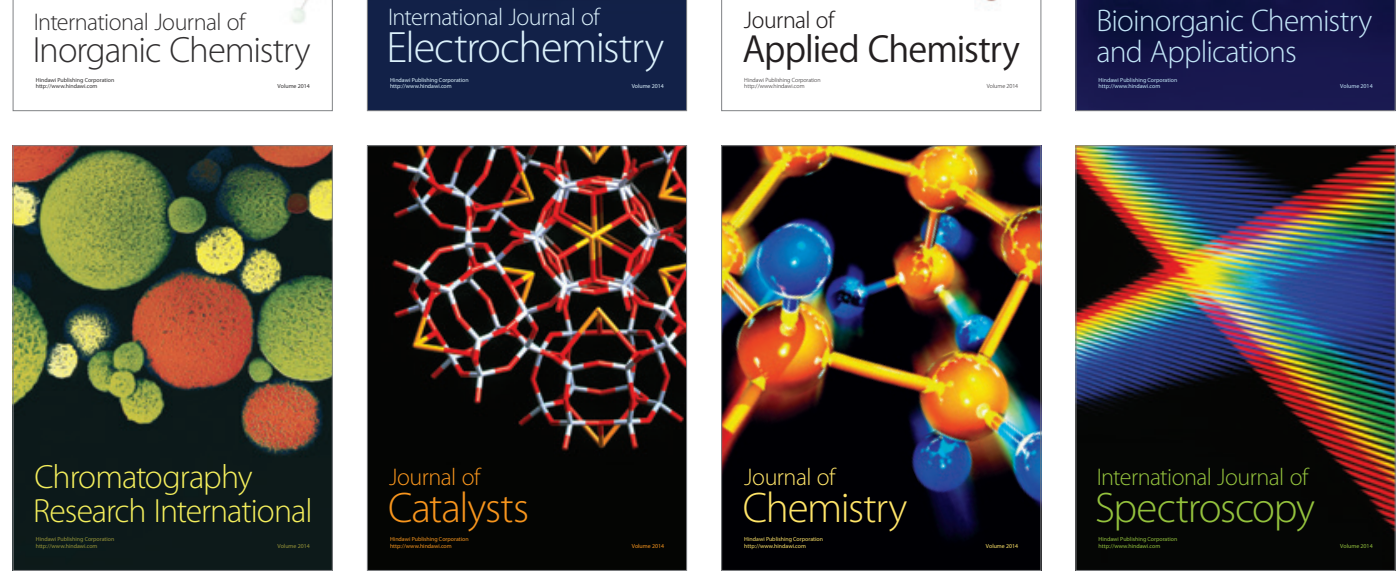